\title{
SELF INTENSIFICATION AND FOCUS INTERPRETATION
}

\author{
KJELL JOHAN SÆBØ \\ University of Oslo
}

\section{ABSTRACT}

\begin{abstract}
Standardly (Safir 2004), the "complex reflexive" SIG + SELF in Dutch or Scandinavian is treated as a special species of anaphora, stronger than SIG alone. This approach has a number of disadvantages, descriptive and theoretical. Theoretically, it is desirable to treat SELF the same as when it modifies another element. Bergeton (2004) argues that a uniform analysis of SELF as an intensifier is feasible and that the descriptive shortcomings of standard treatments can be overcome if intensification is severed from binding (SIG). However, his account is incomplete in a few regards. Building on a formal theory of focus (Rooth 1992), I show that the distribution of simple and complex reflexives - almost complementary in Dutch and Scandinavian, freer in German - can be more fully explained on the basis of a theory of intensification (Eckardt 2001) supplemented by Bidirectional OT (Blutner 1998, 2000, 2002, 2004, 2006).
\end{abstract}

\section{[1] INTRODUCTION}

A number of languages have both "true" and "false" reflexives (Bouchard 1984), or both SELF and SE anaphors (Reinhart and Reuland 1993), serving different functions; specifically, there are predicates where only the former can occur. Norwegian exhibits the complex reflexive seg selv beside the simple reflexive seg. Hellan (1988) argued that basically, these two are in complementary distribution, as suggested by the following examples:

(1) Sangerne akkompagnerte seg \#(selv) på gitar. singers-the accompanied SEG \#(SELF) on guitar

(2) Christina Aguilera har sagt ja til å kle av seg (\# selv). Christina Aguilera has said yes to to dress off SEG (\# SELF)

(3) Gulbransson drakk [seg (\# selv) full]. Gulbransson drank SEG (\# SELF) drunk

(4) $\operatorname{Hun}_{i}$ har sitt eget band med til å akkompagnere [seg (\# selv) $]_{i}$. she $_{i}$ has her own band with to to accompany [SEG (\# SELF) $]_{i}$ 
Hellan developed an ingenious theory to predict this distribution (see Section 2). However, there are problems with this account, both theoretical and descriptive. These problems persist in more recent analyses of this and similar phenomena (Reinhart and Reuland 1993; Safir 2004). I will refer to these analyses collectively as the TRADITIONAL TREATMENT, and I will treat them and their problems, and the facts that (1)-(4) indicate, more extensively in Section 2. In sharp contrast to the traditional treatment, which is basically syntactic, Bergeton (2004) proposes to derive the different distribution of (Danish) sig and sig selv from the meaning of selv. This word is used to modify other individual denoting words than reflexive pronouns, for instance, personal pronouns, and a uniform description as an INTENSIFIER is theoretically attractive. Intensifiers are assumed to supply focus, and focus has to do with alternatives and contrast. Bergeton can answer why sig is preferred over sig selv in cases like (2) and (3) but sig selv is good in cases like (1), but not really why sig selv is preferred over sig - that is, why the intensifier is necessary - in cases like (1). Besides, he does not work with a formal theory of focus (such as Rooth 1992) and intensification (such as Eckardt 2001), so his account is not as precise as it could be. Finally, it is not evident how it can be extended to languages like German, where the intensifier is on the whole less necessary than in Scandinavian or Dutch.

\section{[2] THE TRADITIONAL TREATMENT AND ITS TROUBLES}

Below, I review three theories of SIG + SELF which I take to be representative of the syntactic tradition: Hellan (1988), Reinhart and Reuland (1993), Safir (2004). I first present their key elements, then I discuss what I see as their problems.

\section{[2.1] Three Theories}

According to Hellan, the near complementary distribution of seg and seg selv, as witnessed by (1)-(4), results from a division of labour between seg and selv: The former indicates binding (sloppily, coreference with some accessible subject), while the latter encodes COARGUMENTHOOD.

Thus the fact that seg selv is impossible as a 'long-distance anaphor', as shown by (4), follows from the constraint that binder and bindee be coarguments, as does the alleged fact that seg selv is excluded as a small clause subject, as suggested by (3). Because conversely, the absence of selv bars coargumenthood, the fact that seg selv is necessary in cases like (1) follows as well. The preference for seg alone in cases like (2) is attributed to the hypothesis that with such verbs, the reflexive does not really code an argument. Sloppily, what you do when you wash is not what you do when you wash somebody - it is a different predicate.

The reflexivity theory developed by Reinhart and Reuland (1993) predicts more or less the same facts concerning the Dutch pair zich and zichzelf (and 1st and 2nd person forms). Only SELF anaphors, e.g. zichzelf, reflexivize predicates, cf. (5); 
predicates with SE anaphors are intrinsically reflexive, rendering SELF anaphors redundant, cf. (6).

(5) Bart bewondert zich*(zelf).

Bart admires $\mathrm{ZICH}^{*}(\mathrm{ZELF})$

(6) Petra waste zich(??zelf).

Petra washed zICH(??ZELF)

Since to reflexivize a predicate means to indicate that its object corefers with its subject, SELF small clause subjects and long-distance anaphors are ruled out:

(7) Het publiek danste [zich(\#zelf) warm]. the audience danced $\mathrm{ZICH}$ (\#ZELF) warm

(8) Zij smeekte mij *ichzelf te helpen. she beseeched me * zICHZELF to help

Safir (2004) understands the near complementary distribution of SIG-SELF and SIG in Germanic as a reflex of a competition. He assumes a scale of forms where the former is more dependent than the latter, and a principle requiring the most dependent form available to be used. Together with availability constraints, specifying, for example, that sIG-SELF depends on a local subject and that it could "represent a referential value distinct from what it depends on", these assumptions are to account for all the facts about the distribution of different anaphoric forms, in Germanic and in other languages.

\section{[2.2] Problems}

There are a number of problems, though, shared by the three theories sketched; some of which are addressed by the scholars themselves, some of which are not. Two problems are descriptive in nature, one has a more theoretical status.

The Cross-Linguistic Challenge: How can intrinsic reflexivity vary?

Cross-linguistic variation offers a challenge to any theory of complex reflexives. German, too, has phrases built from the string SIG + SELF - sich selbst - but here the SELF element is optional in many cases where, mutatis mutandis, it is obligatory in Dutch or Scandinavian; "the addition of the SELF form is either disambiguating or emphatic" (Safir 2004, 99). According to Mattausch (2003), the fundamental challenge facing Reinhart's and Reuland's account is that it is not obviously extendable to other languages; in particular, in German or Icelandic, SELF marking is not always mandatory for non-intrinsically reflexive predicates. The same challenge faces Hellan's and Safir's accounts.

Safir counters this challenge by hypothesizing that in German, selbst does not 
form a morphological unit with sich; not entering the numeration by a single selection, sich selbst is not in competition with sich and sich is not obviated from the contexts where SIG-SELF is mandatory in Dutch or Mainland Scandinavian (Safir $2004,100 ; 205)$. This may seem a reasonable enough solution, but there is no independent evidence to support it.

\section{Noncomplementarity}

The claim that verbs like vaske 'wash' are intrinsically or inherently reflexive, meaning that SIG is a nonargument or that the object cannot represent anything distinct from the subject, is intuitively rather weak. Naively, one is tempted to say that something else can absolutely be substituted for sig. Indeed, as conceded by most scholars, the complementarity between SIG and SIG-SELF is not complete: SIG-SELF forms are possible with intrinsically reflexive verbs provided that the discourse justifies them, as illustrated below:

(9) Han begynte å kle av meg. Så kledde han av seg selv også. he began to dress off me then dressed he off SEG SELF too 'He started undressing me. Then he undressed himself too.'

Here, the context provides an alternative - meg 'me' - to the reflexive referent, and this seems to require that (seg be stressed or) seg selv replace seg.

To this, a syntactician may respond that it is only apparently possible to substitute something else (i.a., SIG-SELF) for SIG, because when we do so, we change the verb, going from one variant to another. ${ }^{1}$ SIG and SIG-SELF are not interchangeable - in fact, when we substitute the latter, we select the other variant of the verb, the one that can have an object distinct from the subject. Thus SIG, though it may be an argument, is informationally redundant after all.

And to be sure, there do seem to be two different actions described in the two halves of (9). Or, with reference to (2), if Christina Aguilera undresses, the action is more or less automatic and only semiconscious, whereas if I were to undress her, I should feel at a loss over how to go about it. But the same can be said of predicates where the SELF element is obligatory, such as Norwegian undersøke 'examine'; if a doctor examines herself, she performs a different, this time much less routine, action than if she examines someone else. ${ }^{2}$

It is probably true that SIG and SIG-SELF are never freely interchangeable when bound by a local subject - there will always be a change in the contextual conditions. However, it is very difficult to argue, without risking circularity, that we invariably alter the meaning of the predicate when we substitute one for the other.

[1] See e.g. Safir $(2004,130)$ on "choices of homophonic predicates".

[2] This case is also a counterargument to the theory of Lødrup (2007), who argues that simple and complex reflexives are both used in the local domain but that the simple reflexive is used when the physical aspect of the referent of the binder is in focus. 
In fact, on close inspection, there seem to be some clear cases where we do alter the meaning - cf. (10), some intermediate cases, and some clear cases where we do not alter the meaning, cf. (9) and (11): In a situation where it is appropriate to use just SIG and in one where it is appropriate to use SIG-SELF, you are describing exactly the same action. This, to my mind, is a strong sign that we need more precise tools than those provided in the syntactic tradition.

(10) a. Det er mange anekdoter om folk som har skadd seg it is many anecdotes about people that have injured SEG alvorlig i ekstreme situasjoner uten å merke det. seriously in extreme situations without to notice it

b. Filmens utgangspunkt er 1. verdenskrig, der fem soldater film-the's departurepoint is 1st worldwar where five soldiers som har skadd seg selv, skal henrettes for forræderi. that have injured SEG SELF shall execute-s for treason

(11) a. Trangen til å vaske seg ofte er den vanligste nevrosen. urge-the to to wash SEG often is the commonest neurosis

b. Noen nevrotikere må vaske seg selv eller huset veldig ofte. some neurotics must wash SEG SELF or house very often

In the same vein, it is easy to show that the alleged ban on SIG-SELF forms as small clause subjects, in resultatives or perceptives (cf. (3) and (7)), often fails, and that (in Norwegian) seg and seg selv can overlap in the same type of context without reflecting any change in interpretation, however subtle:

(12) a. I toårsalderen sang hun seg i søvn i stedet for å gråte. in twoyearsage sang she SEG in sleep in stead of to cry

b. Når han skal sove, synger han seg selv i søvn. when he shall sleep sings he SEG SELF in sleep

What can be observed is that the frequency of SIG-SELF forms vs. SIG forms as subjects in resultative small clauses varies with the frequency of referentially distinct DPs in the same context: The more likely the "superordinate" event is to cause a distinct referent to undergo the "subordinate" event, the more likely is a nondistinct referent to be articulated by a SELF form (cf. Section 4.3).

Intensification and Compositionality

The traditional, syntactically based accounts of SIG + SELF anaphors do not answer (or even ask) the question why SELF forms (or, in Romance, SAME forms) are chosen to augment sIG forms. These forms have a use outside the reflexive domain, as intensifiers, modifying other (individual-denoting, type e) DPs, for instance, personal pronouns. Some scholars (Moravcsik 1972, Edmondson and Plank 1978, 
Gast 2006, Siemund and Gast 2006, Zribi-Hertz 1995) have argued that the reflexive usage is historically derivable from, if not synchronically identical to, the intensive (emphatic) usage. In fact, a uniform, synchronic treatment might well be feasible, and if it is, it is clearly desirable. Bergeton (2004) has made a serious attempt at such a treatment (Section 3).

There is a core of common sense in the contention that verbs like vaske 'wash' are intrinsically or inherently reflexive: Washing is typically something you do to yourself, it is a predominantly self-directed action. In most or all cases of locally bound SIG, a case can be made that the predicate denotes such an action. We have also seen that when SIG-SELF figures as a small clause subject, it is not uncommon for somebody else to occupy that position in the same context. König and Siemund (2000) have hypothesized a cross-linguistic correlation between the type of reflexivizing strategy and the self- vs. other-directedness of the predicate: The more marked, or other-directed, a reflexivizing situation, the more marked, or complex, a reflexivizing strategy will be used to encode it.

A marked-form - marked-content correlation such as this is in itself plausible, not least in a perspective of OT pragmatics (cf. Zeevat 2004). Mattausch 2003 has shown how it can have developed as a result of bidirectional learning. What remains to be shown is that SIG-SELF is not only more complex and marked than SIG, having two syllables instead of just one, but that it is ideally suited to the purpose because SELF makes a specific and constructive contribution to the marking of other-directedness - in other words, that the use of SELF (or SAME) to augment SIG is not accidental, but that the meaning of SIG + SELF is a function of the meanings of its parts.

\section{[3] BERGETON AND THE UNIFIED ANALYSIS OF INTENSIFICATION}

Following König and Siemund (2000) in assuming that, across many languages, SELF anaphors are combinations of a SIG anaphor and an intensifier whose overall meaning is a function of that of the two components, Bergeton (2004) develops a semantic-pragmatic analysis of SIG-SELF as the intensified version of SIG. This work represents a radical reinterpretation of the relevant facts and has decisive advantages over most previous work, descriptively and theoretically. However, it is still in need of improvement in some respects. In this section, I will first outline the analysis and point out its strengths; then I will discuss what I perceive as its weaknesses.

\section{[3.1] Adreflexive Intensification}

Bergeton's theory rests on these assumptions:

- Binding and intensification are independent.

- Intensification requires contexts providing alternatives and contrast. 
- Intensification of anaphors is sensitive to predicate meaning and pragmatics (utterance situation and common ground).

- There are four relevant classes of predicates (Bergeton 2004, 160):

(i) Reflexive predicates, presupposing identity of arguments,

(ii) “anti-reflexives", presupposing non-identity of arguments,

(iii) neutral predicates, presupposing nothing of the kind, and

(iv) "hidden" neutrals, coming close to anti-reflexives; presupposing nothing, but evoking expectations of non-identity of arguments.

This theory is theoretically satisfying in a double sense: It is economical, aiming at a uniform analysis of SELF whatever it modifies, and it is explanatory in the sense that the meaning of SELF is assigned a role.

The theory also makes more precise predictions about the distribution of the forms than do earlier accounts (see 2.2). In particular, SIG and SIG-SELF are not predicted to be, in the strict, lexical sense, in complementary distribution, as a large subclass of the "inherently reflexive predicates" are reassigned to a new class of neutral predicates where, depending on the context, both are possible. Likewise, the theory correctly predicts that SIG-SELF forms can be SC subjects; there is no requirement for them to represent coarguments, and again, the choice will depend on whether the context generates a contrast set of alternatives.

Finally, the theory predicts that SIG + SELF forms can be 'long-distance' bindees; in fact, Bergeton contests the traditional notion that when a language has both simplex and complex reflexives and both local and non-local binding, it is the former that are non-locally bound -"Pica's generalization" (Pica 1985), cf. (13), maintaining that intensification is independent of binding and that the distribution of SELF follows basically the same semantic-pragmatic pattern in non-local as in local environments: when the context offers alternatives with which the bindee is explicitly contrasted, as in (14) or (15), sig selv is possible:

(13) Sjeherasad $_{i}$ ba Dunjasad hjelpe $\left[\operatorname{seg}(\# \text { selv) }]_{i}\right.$. Sheherazade $_{i}$ asked Dunyazade help $[\mathrm{SEg}(\# \mathrm{SELF})]_{i}$

(14) a. McArthur, an extremely tough general, feels that the lightly wounded soldiers ought to put up with the pain in order to save painkillers for the truly needing. When he himself got a large piece of shrapnel in his thigh he stubbornly refused to take any kind of painkillers. But in the end the pain became too much for him. So far his principles had dictated him to ask the nurses to give the painkillers to the other soldiers in his ward. 
b. ?Men igår, sent på natten bad McArthur $_{i}$ mig endeligt

But yesterday, late on night-the asked McArthur $_{i}$ me finally

give $\operatorname{sig}_{i}$ (selv) en morfinindsprøjtning.

give $\operatorname{SIG}_{i}$ (SELF) a morphineinjection

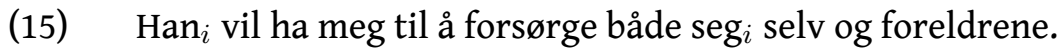

'He wants me to provide for both himself and his parents.'

\section{[3.2] Loose Ends in Bergeton's Account}

Although Bergeton's work represents a significant step in a promising direction, it also leaves some questions unanswered. Among these are:

(i) Why is SELF necessary in many cases - like (1) and (5)?

(ii) Why is SELF less necessary in (say) German than in (say) Dutch?

The Necessity of Intensification

It is evident that the theory is intended to account for the necessity of intensification by SELF in connection with "anti-reflexive" or "hidden neutral" predicates like beundre, cf. (16). These predicates are assumed to induce the presupposition or at least the expectation that their arguments refer to different entities; people do not normally admire themselves. According to Bergeton's "Contrastiveness Condition", intensification requires contexts providing contrasting alternatives. Since this condition is, as it were, lexically satisfied in connection with anti-reflexive or hidden neutral predicates, it is clear that SELF is possible here, but not, strictly, that it is necessary. It would seem that intensification is needed to overcome anti-reflexivity or hidden neutrality, but this is not spelt out, and it does not follow from the analysis; it remains unclear what is wrong with sIG forms in connection with anti-reflexives or hidden neutrals - or what sets it right once SIG is augmented by SELF.

(16) Narcissos sitter og beundrer seg *(selv).

Narcissus sits and admires SEG *(SELF)

\section{The Cross-Linguistic Challenge}

The fact that SIG + SELF is clearly less frequent in German (or Icelandic) than in Dutch or Mainland Scandinavian, noted in Section 2.2, is just as problematic on Bergeton's account as on earlier accounts. With many predicates that correspond to hidden neutral predicates in, say, Danish, sich is possible on its own - even though it is not accented - and selbst intensification is just possible, not necessary. Yet hidden neutrality would seem a universal property - one would not expect it to vary cross-linguistically. 
(17) Sie begleitet sich (selbst) auf dem Klavier. she accompanies SIG (SELF) on the piano

So the challenge is to motivate some linguistic contrast between Dutch and MSc on the one hand and German and Icelandic on the other, to explain how antireflexivity or hidden neutrality, semantic properties of predicates, may relate to intensification differently from one language to another.

Note that precisely because Bergeton's theory is compositional, the option open to Safir (Safir 2004) (see Section 2.2) is here closed: One cannot very well argue that SIG + SELF is a unit in Dutch but not in German, when the cornerstone of the theory is that binding and intensification are independent of each other.

The reason that these issues remain open in Bergeton's analysis may be that he does not work with a formal theory of intensification, such as Eckardt (2001), set in a formal theory of focus and alternatives, such as Rooth (1992). Such a basis would sharpen the theory, also with respect to the facts about which it appears to make valid predictions. Thus the theory seems to explain why SELF is sometimes appropriate and sometimes inappropriate with neutral predicates; but to ascertain these predictions, it is really necessary to seek a firm footing in a formal framework.

\section{[4] ALtERNATIVE SEMANTICS AND BIDIRECTIONAL FOCUS THEORY}

I believe that the problems identified in the last section can be solved - or, at any rate, that solutions can be developed and assessed - if Bergeton's theory is supplemented by a theory of intensification based on a formal theory of focus interpretation. Such a theory of intensification has been proposed by Eckardt (2001), building on the focus theory of Rooth (1992), Alternative Semantics. In addition, there will be a need to augment Alternative Semantics by Bidirectional Optimality Theory, developed by Blutner (Blutner 1998 and later work).

\section{[4.1] Eckardt's Theory of Intensification}

Eckardt's theory is primarily about the German intensifier selbst ( $\approx$ English intensifying -self, -selves) as it appears in (18), adnominally, or (19), adverbally.

(18) Ich möchte spätestens mit 17 ein Kind haben, weil ich es am besten I wantto latest at $17 \mathrm{a}$ child have because I it at best finde, früh Kinder zu bekommen, um mein Kind, find early children to get for my child wenn es selbst Teenager ist, zu verstehen. self teenager is to understand 
(19) Ihr Kind spürt, dass Sie mit ihm nicht zufrieden sind - und es ist your child senses that you with it not content are - and it is selbst nicht zufrieden.

itself not content

The theory is very simple. It says:

INTENSIFICATION ACCORDING TO ECKARDT

The intensifier denotes the identity function on type e entities.

From this assumption, the following follows:

- The expression denoting the type e argument, the so-called Associate, is a name, variable, (personal or reflexive) pronoun, or definite description.

- The associate is out of focus (or in focus together with the intensifier), and the intensifier is in focus (alone or together with the associate) - or else intensification would be redundant.

THE NET EFFECT OF INTENSIFICATION

The net effect of selbst is to add focus, giving rise to focus presuppositions in Alternative Semantics, the focus theory of Rooth (1992).

Let us work our way through (20).

(20) As Elizabeth Brinker cares for her mother, she knows she herself ${ }_{\mathrm{F}}$ is [at risk of inheriting $]_{\mathrm{F}}$ Alzheimer's disease.

We have the adnominal case: She and herself form a constituent, she herself. Suppose that the ordinary semantic value of she is $x$, bound in a presupposition. Then the ordinary semantic value of she herself is the same, $x$, and so is also the focus semantic value of she. But the focus semantic value of she herself is the set of values of alternatives to the identity function at $x$ (the focus semantic value of herself being the set of alternatives to that function):

THE FOCUS SEMANTIC VALUE OF she herself

$\left\{z \mid\right.$ there is an alternative $f$ to $\operatorname{ID}_{<e, e>}$ such that $\left.z=f(x)\right\}$

Alternatives to the identity function on individuals are operations on individuals that do not map them onto themselves but onto others. At sentence level, the two foci are interpreted in terms of a focus presupposition: 
THE FOCUS PRESUPPOSITION OF (20)

There is a proposition $\phi$ such that there is a function $f \approx \mathrm{ID}_{<e, e\rangle}$ and there is a relation $R \approx$ at risk of inheriting such that $\phi=R($ alzheimer's $)(f(x))$

This presupposition is verified in the context: $f=$ one's mother, $R=$ afflicted with .

To be sure, there is more to say about, in particular, adverbal intensification in Eckardt's theory (see also Sæbø 2005). However, since intensification of reflexives is adnominal intensification, we can concentrate on this.

\section{[4.2] Adreflexive Intensification in Eckardt's Theory}

Eckardt does not explicitly consider selbst intensification of reflexive pronouns all her examples have subject associates - but the theory can accommodate it. As a step towards it, consider intensification of a Norwegian object pronoun:

(21) Glahn elsker drømmen om Edvarda mer enn han elsker henne selv. Glahn loves dream-the of Edvarda more than he loves her SELF

(22) De gode gjerningene hennes har reelt sett gagnet henne selv. the good deeds hers have really seen benefitted her SELF

As the focus semantic value of henne selv, we can maintain the focus semantic value of she herself defined above, with $x$ as the focus and ordinary semantic value of henne. The focus presupposition in terms of which focus is interpreted at sentence level might here be (assuming $y$ to represent the good deeds):

THE FOCUS PRESUPPOSITION OF (22)

There is a proposition $\phi$ such that there is a function $f \approx \mathrm{ID}_{<e, e\rangle}$ and there is an operation $O \approx$ really such that

$\phi=O($ benefit $(y)(f(x)))$

Again, this is verified in the context: $f=$ one's beneficiaries, $O=$ supposedly.

From here, there is a short step to the case where the associate is a reflexive. Consider first the intensification of a reflexive object of a "neutral predicate" (in Bergeton's term), where its appropriateness in general depends on the context:

(En barberer barberer alle som ikke barberer seg selv
a barber shaves everyone that not shaves SEG SELF
ingen andre.) Barberer denne barbereren seg selv?
noone else shaves this barber SEG SELF

Applying the same method to this case as to (20) and (22), we can compute this focus presupposition (assuming $x$ to represent the barber): 
THE FOCUS PRESUPPOSITION OF (23)

There is a proposition $\phi$ such that there is a function $f \approx \operatorname{ID}_{<e, e>}$ such that

$\phi=\operatorname{shaves}(f(x))(x)$

This is verified in the context, for one's barbershop customers instantiating $f$.

Now there is an alternative to this method, modifying it slightly as regards the focus structure of the intensified phrase. Eckardt assumes that the intensifier is in focus all by itself, forming a separate focus domain. The associate is out of focus. This is reasonable as long as - and this is the case she considers - the associate is a familiar referent, a name, personal pronoun, or definite description. But even then, it is imaginable that the intensifier, inherently accented, forms a focus domain together with the associate; cf. the following alternatives:

a. She [herself $]_{\mathrm{F}}$ is [ at risk of inheriting $]_{\mathrm{F}}$ Alzheimer's disease.

b. [she herself $]_{\mathrm{F}}$ is [at risk of inheriting $]_{\mathrm{F}}$ Alzheimer's disease.

a. Barberer denne barbereren seg $[\operatorname{SELV}]_{\mathrm{F}}$ ?

b. Barberer denne barbereren $[\operatorname{seg} \operatorname{SELV}]_{\mathrm{F}}$ ?

And when the associate is a reflexive, the option that it and the intensifier are in focus together, corresponding to (25b), may appear to be particularly viable. Then, the focus presupposition is simplified, since the focus semantic value of the intensified pronoun or anaphor is simply the set of alternatives to $x:^{3}$

THE FOCUS PRESUPPOSITION OF (23) (ALTERNATIVELY)

There is a proposition $\phi$ such that there is a $y \approx x$ such that

$\phi=\operatorname{shaves}(y)(x)$

The central question is how the associate relates to focus if it is not intensified:

(i) Is it out of focus (old information)? Or:

(ii) Is it in focus with something else - the predicate?

The facts about the distribution of SIG (SELF) in connection with anti-reflexive predicates (cf. Section 4.4) seem to point in the direction of 2 . That is, there is reason to assume (26b), with wide focus and so-called informational integration (Jacobs 1999), instead of (26a), where the reflexive is out of focus:

$$
\begin{aligned}
& \text { a. Hun }[\text { vasker }]_{\mathrm{F}} \text { seg. } \\
& \text { she washes SIG }
\end{aligned}
$$

[3] Eckardt derives so-called centrality effects from alternatives to the identity function. It is debatable whether there is a real difference between the two options in this regard, or whether centrality should be explained otherwise. Anyway, centrality effects do not seem to play a central role in connection with intensified anaphors. 
b. Hun [ vasker seg $]_{\mathrm{F}}$.

she washes SIG

And in that case, the ceteris paribus situation with intensification is surely not the one where the associate is out of focus by itself, corresponding to (25a) and (27a), but the one where the associate and the intensifier are in focus together, corresponding to (25b) and (27b). This is the structure I will henceforth assume.
a. Hun $[\text { vasker }]_{\mathrm{F}} \operatorname{seg}[\operatorname{selv}]_{\mathrm{F}}$. she washes SIG SELF
b. Hun $[\text { vasker }]_{\mathrm{F}}[\text { seg selv }]_{\mathrm{F}}$. she washes SIG SELF

\section{[4.3] Predicate Meaning and Local vs. Global Focus Justification}

On the theory of focus interpretation and intensification as applied to SIG, a sentence with [SIG SELF] presupposes that there is a proposition corresponding to the sentence but for the substitution of some alternative for the focus or foci, in particular, for the sIG referent. Generally, the existence of such a proposition can be given contextually, in the discourse, or more globally, through our lexical and encyclopaedic knowledge.

THE FOCUS PRESUPPOSITION OF $a p$ SIG SELF

There is a proposition $\phi$ such that there is a $y \approx a$ such that $\phi=P(y)(a)$

It has often been noted that the predicates that Bergeton calls neutral (at any rate those that are traditionally called intrinsically reflexive) require "discourse justification" for their reflexive to be intensified (e.g., Reinhart and Reuland 1993, fn. 15). This means that the focus presupposition arising from the intensifier must be justified contextually; say, (2) with seg selv is not felicitous out of the blue. On the other hand, the "anti-reflexive" and "hidden neutral" predicates are felicitous with seg selv without contextual support, so the focus presupposition is evidently justified lexically. In other words: By virtue of their meaning, their other-directedness, the anti-reflexives and the hidden neutrals provide propositions involving alternative referents, verifying the presupposition induced by the intensifier "globally", as opposed to the neutrals, where it must be verified "locally".

In this perspective, resultative constructions where simple and intensified reflexives coexist as small clause subjects, with a more or less pronounced bias for one or the other from case to case, form an intermediate stage; and Bergeton's theory is very well adapted to account for this gradient variation. Often enough, intensification does not need to be justified contextually, it depends on whether 
it would be sufficiently natural for another referent to occupy the relevant role in relation to the caused event as a result of the causing event. So it does not depend on one predicate but on two predicates in a resultative relation.

Note, for example, that the frequency relation between gråte seg selv $i$ søvn ('cry -self to sleep') and gråte seg i søvn (by a Google search) is at about $1: 100$, while that between synge seg selv i søvn ('sing-self to sleep') and synge seg $i$ søvn is at about $1: 1$.
a. I toårsalderen sang hun seg $\mathrm{i}$ søvn $\mathrm{i}$ stedet for å gråte. in twoyearsage sang she sIG in sleep in stead of to cry
b. Når han skal sove, synger han seg selv i søvn. when he shall sleep, sings he SIG SELF in sleep

This can be taken to reflect that the focus presupposition coming from selv is much more readily justified when singing is the causing activity - we normally sing others to sleep - but that presupposition can still be accommodated when crying is the causing activity.

Note, by the way, that there are also neutral predicates where there is no clear preference for simple reflexives and complex ones do not require discourse justification, and where, as in the resultative constructions, this coexistence is not connected to a polysemy or a "doppelgänger" or "proxy" interpretation effect. In Norwegian, such truly neutral predicates include redde 'save', ofre 'sacrifice', forsvare 'defend', beskytte 'protect', and ditransitive nekte 'deny'.

\section{[4.4] The Necessity of Intensification and Bidirectional Focus Theory}

As stated in Section 3.2, Bergeton's theory as it stands does not really answer the question why intensification is necessary when a reflexive object is bound by the subject of an anti-reflexive or a hidden neutral predicate. On the grounds of the presupposition or expectation coming with such predicates - that the arguments refer to different entities - it seems clear that sentences with reflexives constitute presupposition failures or expectation denials. However, it is not clear how intensification would help; adding focus adds a(nother) presupposition, one verified through the predicate, as we have seen. But that does not undo the first presupposition failure or cause the expectation denial not to be grave anymore.

The key to a solution to this problem lies in considering what is signalled by the focus structure of the sentence with the simple reflexive, without intensifier. This depends on what that focus structure is. As suggested in Section 4.2, there is in general a choice between assuming that the reflexive is out of focus, cf. (29), and assuming that it is in focus together with the predicate, cf. (30):

$$
\begin{aligned}
& \text { \#Han [beundrer }]_{\mathrm{F}} \text { seg. } \\
& \text { he admires SIG }
\end{aligned}
$$




$$
\begin{aligned}
& \text { \#Hun [beundrer seg }]_{\mathrm{F}} \text {. } \\
& \text { she admires SIG }
\end{aligned}
$$

Eckardt (2001) appears to only consider the structure corresponding to (29), but that is probably only because the associates she considers are all anaphoric in the discourse semantic sense (names, definite descriptions, personal pronouns). Reflexives are different. And if we choose the structure corresponding to (30), we have a way of explaining the infelicity of simple reflexives in these contexts.

Jacobs (1999) has developed a theory about the grammar, semantics, and pragmatics of "wide focus" constructions such as those where a predicate and an argument (usually a theme argument) form one focus domain with one accent (on the more informative constituent; usually the argument, but the predicate if the argument is e.g. an indefinite pronoun). The less informative constituent is said to be informationally integrated, or nonautonomous; the predicate and the argument function as one informational unit and must be processed semantically in one step (Jacobs 1991, 18) and $(1999,68)$. Here are two typical examples:

(31) They have $[\text { discovered GOLD }]_{\mathrm{F}}$.

(32) They have $[\text { discovered something }]_{\mathrm{F}}$.

This notion of informational unity is difficult to make precise; in particular, the semantic and pragmatic - contextual and lexical - constraints on integration have proven elusive. The basic problem is this: Focus theory has a story to tell about the constraints on one or more narrow foci versus wide focus, these being relatively strong focus presuppositions, but in the opposite direction, the focus presupposition is weaker, so a preference for, say, two narrow foci, one for the predicate and another for the argument, is prima facie mysterious.

Thus (33) will carry the focus presupposition that there is an alternative $a_{1}$ to stolen and there is an alternative $a_{2}$ to a ring such that there is a proposition, sloppily, of the form he has $a_{1} a_{2}$, while (34) will just carry the presupposition that there is an alternative $a_{3}$ to stolen a ring such that there is a proposition, sloppily, of the form he has $a_{3}$. The former subsumes the latter.

He has $[\text { stolen }]_{\mathrm{F}}[\text { a RING }]_{\mathrm{F}}$.

He has [ stolen a RING $]_{\mathrm{F}}$.

However, recent developments in pragmatics, Bidirectional OT (Blutner 1998 and later work), can provide a bridge between Focus Theory and Informational Integration. The basic idea is that expressions compete with each other for interpretations (and vice versa), and when one expression loses to another for an interpretation, an alternative interpretation wins as the optimal interpretation for that expression. Thus a sentence with a relatively nonspecific focus interpreta- 
tion, for example, (34), will not only not communicate the more specific focus interpretation of (33); it will actually communicate the opposite, namely, there are not alternatives to stolen and to a ring - to the VP as a whole there are alternatives, but not to the predicate and the argument separately.

As shown in (Sæbø 2007), this optimal interpretation - an implicature which, though basically conversational, can become conventional (Blutner 2006) - boils down to saying that the predicate is sufficiently predictable from the argument $a$ ring, plus that there are no local alternatives to the predicate in the discourse.

This reasoning carries over to the two competitors (30) and (35), only that here, the predictability requirement for wide focus is reversed - for (30) to be felicitous, the argument seg must be sufficiently predictable from the predicate, plus that the discourse must not overtly provide alternatives to it.

$$
\begin{aligned}
& \text { Han }[\text { beundrer }]_{\mathrm{F}}[\text { seg selv }]_{\mathrm{F}} \text {. } \\
& \text { he admires SIG SELF }
\end{aligned}
$$

But of course, the reflexive is not, and cannot be, sufficiently predictable on the basis of a verb with this meaning. This holds true regardless of discourse relations otherwise known to facilitate relative predictability.

Generally, complementing the focus presupposition of $a P_{\mathrm{F}}[\operatorname{sig} \mathrm{SELF}]_{\mathrm{F}}$, we will (in languages like Norwegian), have a (presupposition and an) implicature for $a[P \text { sig }]_{\mathrm{F}}$, along the following lines:

THE FOCUS PRESUPPOSITION OF $a P_{\mathrm{F}}[\text { sig SELF }]_{\mathrm{F}}$

There are propositions $\phi$ s.t. there is an $R \approx P$ and a $y \approx a$ such that $\phi=R(y)(a)$

THE FOCUS PRESUPPOSITION AND IMPLICATURE OF $a[P \text { sig }]_{\mathrm{F}}$

There are propositions $\phi$ s.t. there is a $Q \approx P(a)$ such that $\phi=Q(a)$, BUT NOT such that there is a $R \approx P$ and a $y \approx a$ such that $\phi=R(y)(a)$

For $P$ a neutral predicate, when the sentence is uttered relatively out of the blue, so that there are no overt alternatives to predicate and argument separately, the implicature will as a rule be appropriate. But for $P$ an anti-reflexive predicate or a hidden neutral predicate, even when there is no local motivation for one focus for the predicate and one for the argument, there will always be a global motivation, as long as there are alternatives to the predicate-argument merge; neither is sufficiently predictable from the other to justify wide focus. The focus presupposition of two separate foci will be verified on a lexical-conceptual basis, and we can assume that this accounts for the necessity of the intensifier. 


\section{[4.5] The Role of Self across Languages: A Suggestion}

Recall from 2.2. and 3.2 that while in Dutch and Mainland Scandinavian, there are many predicates where a locally bound SIG argument must be intensified, in German or Icelandic, SELF intensification is much more rarely mandatory. A syntactician can maintain that SIG + SELF somehow has a tighter structure in the languages where complex reflexives are often obligatory (Safir 2004, 205). However, if binding is independent of intensification, that strategy is unavailable. The relative freedom of German SELF, illustrated in (38), presents a problem.

(36) Anstatt sich (selbst) anzuklagen, lernt man sich (selbst) zu akzeptieren instead SIG (SELF) accuse learns one SIG (SELF) to accept und anzunehmen. and embrace

All three verbs correspond to "hidden neutral" verbs in Mainland Scandinavian, necessitating SELF; and it is easy to agree that they are all "other-directed" in the sense that it is much more common to accuse, accept and embrace somebody else than to accuse, accept and embrace oneself. As we have seen, this is enough to force intensification in Mainland Scandinavian (but not in German).

The explanation given in Section 4.4 (based on Bergeton's analysis) is that if we do not intensify, we implicate that there are no salient alternatives to the bindee, globally (lexically) or locally (contextually). Other-directedness in a predicate means that there are salient alternatives, lexically; thus the implicature we make when we do not intensify is systematically contradicted by the predicate we use. The same conclusion would seem inescapable for German.

However, reconsider the focus structure assumed for the not intensified cases in MSc, inappropriate for hidden neutral and anti-reflexive predicates, in 4.4. Both (29) and (30) were candidates for the not intensified case, alternating with (35), the intensified case; both were considered but (30) was selected. The difference is this: whereas in (29) the reflexive is out of focus when it is not intensified, in (30) it is in focus together with the predicate, forming one informational unit. The main motive for choosing this latter option is that exactly because predicate and reflexive argument form (in the sense of Jacobs 1999) one informational unit, the not intensified case is predicted to obey semantic and pragmatic constraints parallel to those that informational integration between predicate and argument obey generally: One must be sufficiently predictable from the other; otherwise, the two must be in focus separately.

When in German, however, the not intensified case is evidently not subject to the same constraints, there may be reason to reconsider the focus structure corresponding to (29), cf. (37) and (38): 
gestions by several scholars, has been developed into a coherent theory by Bergeton (2004). In many respects, that work speaks for itself, arguing that a uniform treatment of intensifiers wherever they occur is theoretically attractive, avoiding duplication and stipulation, and that it solves the descriptive problems facing the traditional approach; in particular, it is no longer necessary to defend, in ways so often running counter to intuition, the postulate of a complementary distribution between the simple and the complex anaphor, predicting things to be impossible that common sense says are possible.

On the other hand, the novel approach risks predicting too much flexibility. What is clear is that the intensifier, introducing a (focus) presupposition (the Contrastiveness Condition in Bergeton's framework), will impose constraints on the context or the predicate or both. It is less clear what makes it necessary (and sufficient) in many contexts and - in some, but not all, relevant languages - with many predicates. Bergeton ascribes to these predicates a presupposition or expectation to the effect that the subject and object refer to different things, a move which does not yet answer the open issues.

I have tried to show that the way to complete Bergeton's account and retain a viable theory in the novel, pragmatic-semantic line is to embed it in a formal theory of focus and intensification, exploiting the options offered in this theory, and to complement it with Bidirectional Optimality Theory. Not only does this strategy seem to yield the right results regarding the discourse-triggered necessity of adreflexive intensification generally and its predicate-triggered necessity in a language like Norwegian; it offers a suggestion about the absence of this latter necessity in a language like German. Thus the novel theory, dividing the labor of complex anaphors between syntax and information structure, is intensified.

\section{REFERENCES}

Bergeton, U. 2004. The Independence of Binding and Intensification. Ph. D.thesis, University of Southern California.

Blutner, R. 1998. Lexical Pragmatics. Journal of Semantics 15, 115-162.

Blutner, R. 2000. Some Aspects of Optimality in Natural Language Interpretation. Journal of Semantics 17, 189-216.

Blutner, R. 2002. Lexical Semantics and Pragmatics. In F. Hamm and E. Zimmermann (eds.), Linguistische Berichte Sonderheft, volume 10, pages 27-58, Hamburg: Helmut Buske Verlag.

Blutner, R. 2004. Pragmatics and the lexicon. In L. R. Horn and G. Ward (eds.), The Handbook of Pragmatics (Blackwell Handbooks in Linguistics), pages 488-514, Oxford: Blackwell Publishers. 
Blutner, R. 2006. Embedded Implicatures and Optimality Theoretic Pragmatics. In T. Solstad, A. Grønn and D. Haug (eds.), A Festschrift for Kjell Johan Scebø, pages 11-29, University of Oslo.

Bouchard, D. 1984. On the Content of Empty Categories. Dordrecht: Foris.

Eckardt, R. 2001. Reanalysing selbst. Natural Language Semantics 9, 371-412.

Edmondson, J. and Plank, F. 1978. Great Expectations: An intensive self analysis. Linguistics and Philosophy 2, 373-413.

Gast, V. 2006. The Grammar of Identity: Intensifiers and Reflexives in Germanic Languages. Routledge Studies in Germanic Linguistics, Address: Routledge (Taylor and Francis).

Hellan, L. 1988. Anaphora in Norwegian and the Theory of Grammar. Dordrecht: Foris. Jacobs, J. 1991. Focus Ambiguities. Journal of Semantics 8(1-2), 1-36.

Jacobs, J. 1999. Informational Autonomy. In P. Bosch and R. van der Sandt (eds.), Focus: Linguistic, Cognitive and Computational Perspectives, Cambridge University Press, 56-81.

König, E. and Siemund, P. 2000. Reflexives: Forms and Functions. Philadelphia: John Benjamins, 41-74.

Lødrup, H. 2007. A New Account of Simple and Complex Reflexives. Journal of Comparative Germanic Linguistics 10, 183-201.

Mattausch, J. 2003. Optimality theoretic pragmatics and binding phenomena. In R. Blutner and H. Zeevat (eds.), Optimality Theory and Pragmatics, pages 63-91, Basingstoke: Palgrave Macmillan.

Moravcsik, E. 1972. Some cross-linguistic generalizations about intensifier constructions. CLS 8, 217-277.

Pica, P. 1985. Subject, tense and truth: Towards a modular approach to binding. In H. Obernauer and J.-Y. Pollock (eds.), Grammatocal Representation, Dordrecht: Foris, 259-291.

Reinhart, T. and Reuland, E. 1993. Reflexivity. Linguistic Inquiry 24, 657-720.

Rooth, M. 1992. A Theory of Focus Interpretation. Natural Language Semantics 1, 75-116.

Safir, K. 2004. The Syntax of Anaphora. Oxford Studies in Comparative Syntax, New York: Oxford University Press. 
Siemund, P. and Gast, V. 2006. Rethinking the relationship between selfintensifiers and reflexives. Linguistics 44, 343-381.

Sæbø, K.J. 2005. Intensifying self in Germanic: A Reanalysis. In The Stockholm Workshop on Contrast, Information Structure and Intonation.

Sæbø, K.J. 2007. Focus Interpretation in Thetic Statements: Alternative Semantics and OT Pragmatics. Journal of Logic, Language and Information 16(1), 15-33.

Zeevat, H. 2004. Markedness. In Asatiani R., R. K. Balogh, G. Chikoidze, P. Dekker and D. De Jongh (eds.), Proceedings of the 5th International Symposium on Language, Logic and Computation, Tbilisi, 183-190.

Zribi-Hertz, A. 1995. Emphatic or reflexive? On the endophoric character of French lui-même and similar complex pronouns. Journal of Linguistics 31, 333-374.

AUTHOR CONTACT INFORMATION

Kjell Johan Sæbø

University of Oslo

Dept. of Literature, Area Studies and European Languages

P.b. 1003, Blindern

$\mathrm{N}-0315$ Oslo

Norway

k.j.sabo@ilos.uio.no 